\title{
LOGÍSTICA REVERSA: um estudo na cadeia produtiva da linha branca
}

\section{Jorlane Clisse Silva da Costa ${ }^{1}$ Eduardo Otávio Ferreira Vasconcelos ${ }^{2}$ Gilson Scholl Pires ${ }^{3}$}

Resumo: O presente artigo faz referência à logística reversa, a qual se encontra dentro da nova demanda mundial que tange a ordem da sustentabilidade. A pesquisa foi apresentada de forma qualitativa e descritiva, com o objetivo de verificar como uma empresa de grande porte do segmento da linha branca trabalha a logística reversa de pós-consumo. Obteve-se dados que explanam como a logística reversa é um diferencial para a organização e como ela auxilia o processo logístico no fluxo inverso, no qual a mesma é efetiva no descarte correto e adequado dos produtos da linha branca.

Palavras-chave: Logística Reversa; Pós-consumo; Linha Branca.

\footnotetext{
1 Bacharelado em Administração/Faculdade Metropolitana da Amazônia, Brasil. E-mail: jorlane_clisse@hotmail.com.

2 Mestre em Gestão e Desenvolvimento Regional pela Universidade de Taubaté - UNITAU; Professor da Faculdade Metropolitana da Amazônia, Brasil, E-mail: vasconcelos_edu@yahoo.com.br.

3 Mestre em Administração pela Universidade da Amazônia - UNAMA; Professor da Faculdade Metropolitana da Amazônia, Brasil. E-mail: gilson.scholl@gmail.com.
} 